\title{
WINDOWS COMMUNICATION FOUNDATION UNTUK AUDIOBOOK DONGENG BAGI ANAK PENYANDANG TUNANETRA
}

\author{
Yuli Purwati ${ }^{1}$, Dadang Wahyu Utomo², Fandy Setyo utomo*3, Wiga Maulana Baihaqi ${ }^{4}$ \\ ${ }^{1,2}$ Informatika, STMIK Amikom Purwokerto, ${ }^{3}$ Sistem Informasi, STMIK Amikom Purwokerto \\ ${ }^{4}$ Teknologi Informasi, STMIK Amikom Purwokerto \\ Email: 1yulipurwati@amikompurwokerto.ac.id, 2dadangwahyu05@gmail.com, \\ ${ }^{3}$ fandy_setyo_utomo@amikompurwokerto.ac.id, ${ }^{4}$ wiga@amikompurwokerto.ac.id \\ *Penulis Korespondensi
}

(Naskah masuk: 18 April 2019, diterima untuk diterbitkan: 10 Februari 2020)

\begin{abstract}
Abstrak
Anak penyandang tunanetra memiliki keterbatasan dalam mengakses informasi, hiburan, dan hal lain yang bisa diakses anak normal. Salah satu keterbatasan yang tidak mampu dilakukan oleh anak tersebut yakni membaca dongeng. Buku dongeng adalah salah satu yang dibutuhkan oleh anak untuk mengasah daya imajinasi dan kreatifitasnya. Buku dongeng biasanya dilengkapi dengan ilustrasi yang menarik untuk anak. Bagi anak penyandang tunanetra hal tersebut tidak bisa dilakukan. Mereka tidak dapat melihat gambar maupun tulisan di dalam buku dongeng. Namun mereka masih dapat mendengar cerita dongeng dari orang lain. Membaca dongeng membutuhkan ketrampilan khusus karena tidak hanya sekedar membaca tapi juga mengilustrasikan gambar dan teks di buku dongeng sesuai cerita dan karakter dari tokoh-tokoh yang ada di dalam buku sehingga anak seolah-olah masuk dalam cerita di buku tersebut meskipun mereka tidak melihat gambar yang ada di buku. Penelitian ini bertujuan merancang dan membangun Windows Communication Foundation untuk aplikasi Audiobook dongeng agar dapat dimanfaatkan oleh anak penyandang tunanetra. Penelitian ini dilakukan dengan 3 tahapan, yaitu analisis sistem, desain sistem, serta implementasi dan pengujian sistem. Hasil riset ini adalah perangkat lunak Windows Communication Foundation dengan 3 layanan, yakni layanan untuk menambah data audio dongeng, layanan untuk memilih dan memutar audio dongeng, dan layanan untuk melihat daftar audio dongeng. Berdasarkan hasil pengujian terhadap Windows Communication Foundation, seluruh layanan tersebut telah berfungsi dengan baik.
\end{abstract}

Kata kunci: dongeng, tunanetra, audiobook, windows communication foundation.

\section{WINDOWS COMMUNICATION FOUNDATION FOR FAIRYTALE AUDIOBOOKS FOR BLIND CHILDREN}

\begin{abstract}
Children with visual impairments have limitations in accessing information, entertainment, and other things that can be accessed by normal children. One of the limits that cannot be done by the child is reading a fairy tale. A fairy tale book is one that is needed by children to hone their usability and creativity. A fairy tale book that is usually equipped with exciting illustrations for children. For children with visual impairments, this cannot be done. They cannot see pictures or writings in fairy tales books. But they can still hear tales from other people. Reading a fairy tale needs special skills such as how to read it aloud and how to illustrate pictures and texts in a fairytale book according to the stories and characters in it. Children might feel that they are involved in the story even though they could not see the picture given. The purpose of the research is to design and to develop Windows Communication Foundation for the fairytale Audiobook application to be used by children with visual impairments. This research was conducted in 3 stages, namely system analysis, system design, and system implementation and testing. The results of this study are Windows Communication Foundation software with three services, namely services to add audio data tales, services to select and play tale audio, and services to view a list of fairy tales audio. To conclude, the result of testing of the Windows Communication Foundation shows that all these services have been well equipped.
\end{abstract}

Keywords: fairytale, blind, audiobook, windows communication foundation

\section{PENDAHULUAN}

Anak penyandang tunanetra memiliki keterbatasan dalam mengakses informasi, hiburan, dan hal lain yang bisa diakses anak normal. Salah satu keterbatasan yang tidak mampu dilakukan oleh anak tersebut yakni membaca dongeng. Buku dongeng adalah salah satu yang dibutuhkan oleh 
anak untuk mengasah daya imajinasi dan kreatifitasnya. Dongeng umumnya bisa dibacakan sejak anak masih dalam kandungan sampai dengan maksimal usia 10 tahun. Melalui dongeng orang tua juga dapat menanamkan nilai-nilai moral serta nasihat dengan cara yang mudah diterima oleh anak.

Studi yang dilakukan oleh (Azkiya dan Iswinarti, 2016) menjelaskan bahwa mendengarkan dongeng memiliki pengaruh yang signifikan terhadap kecakapan bahasa pada anak pra-sekolah, karena dalam mendongeng terjadi pembelajaran untuk memperoleh perbendaharaan kata baru, menilai, serta memahami fakta baru, sedangkan studi yang dilakukan oleh (Fitroh dan Sari, 2015) dengan sampel penelitian anak usia 2.5 - 3.5 tahun menunjukkan hasil penelitan bahwa dongeng merupakan cara efektif untuk menanamkan karakter kepada anak usia dini karena memberikan contoh dan pembiasaan yang baik kepada anak melalui dongeng. Selanjutnya, penelitian (Indriastuti, 2015) yang menilai keberhasilan instrumen pembelajaran audio menggunakan Cerita Pendidikan Berkarakter untuk Tunanetra (CERDIKTERA) menunjukkan bahwa dengan media tersebut terjadi kenaikan impuls belajar peserta didik, interpretasi materi, memiliki aksesibilitas, dan memiliki tingkat karakter yang mampu memberikan pendidikan tingkah laku.

Buku dongeng biasanya dilengkapi dengan ilustrasi yang menarik bagi anak-anak. Untuk anak usia balita biasanya buku dongeng sangat minim teks namun penuh dengan gambar agar anak dapat berimajinasi dengan gambar tersebut sekalipun belum bisa membaca.

Bagi anak penyandang tunanetra hal tersebut tidak bisa dilakukan. Mereka tidak dapat melihat gambar maupun tulisan di dalam buku dongeng. Namun mereka masih dapat mendengar cerita dongeng dari orang lain. Membaca dongeng membutuhkan ketrampilan khusus karena tidak hanya sekedar membaca tapi juga mengilustrasikan gambar dan teks di buku dongeng sesuai cerita dan karakter dari tokoh-tokoh yang ada di dalam buku sehingga anak seolah-olah masuk dalam cerita di buku tersebut meskipun mereka tidak melihat gambar yang ada di buku.

Bersumber pada ruang lingkup dan permasalahan tersebut, riset ini bermaksud merancang dan membangun Windows Communication Foundation (WCF) untuk aplikasi Audiobook dongeng agar dapat dimanfaatkan oleh anak penyandang tunanetra. WCF berfungsi memberikan layanan yang dapat diimplementasikan di berbagai platform, baik itu berbasis desktop, web, maupun mobile. Harapan kami melalui pemanfaatan WCF pada aplikasi audiobook dongeng, anak-anak tunanetra mendapatkan media pendidikan sekaligus hiburan sama seperti anak normal lainnya.

Penelitian aplikasi audiobook yang dimanfaatkan sebagai media informasi dan pendidikan bagi tunanetra sudah pernah dikembangkan oleh beberapa peneliti yang dijadikan sebagai referensi pada penelitian ini diantaranya penelitian (Camalia, Susanto, \& Susilo, 2016) membuat media audiobook dilengkapi dengan alat peraga dalam pembelajaran IPA Fisika materi getaran dan gelombang di SLB-A (Tunanetra) yang menunjukkan hasil kelayakan dan keefektifan media tersebut dalam mendukung proses pembelajaran bagi penyandang tunanetra. Penelitian ini merupakan riset bersifat Research and Development (R\&D) dengan perancangan prototipe produk menggunakan pre-experiment design dengan one group pretestposttest.

Riset selanjutnya dilakukan oleh (Paramitha, Kesiman, \& Arthana, 2014) yang mengembangkan aplikasi berbasis Android bagi penyandang Tuna Netra, yakni Digital Interactive Storyteller. Pada aplikasi ini akan disajikan audio dongeng dalam bahasa Inggris. Aplikasi yang dikembangkan akan lebih interaktif dengan pengguna. Pengguna mampu menentukan alur dongeng secara mandiri berdasarkan jawaban yang diberikan pengguna. Jawaban dari pengguna akan menentukan akhir cerita.

Selanjutnya, studi yang dilakukan oleh (Pratama, dkk., 2016) mengembangkan hasil rekaman menjadi novel audio bagi penyandang tuna netra. Penulis mengembangkan alat berbasis Android dan Arduino yang memanfaatkan modul bluetooth guna melakukan invokasi terhadap hasil rekaman yang telah disunting. Hasil rekaman tersebut dapat didengarkan oleh penyandang tuna netra menggunakan headset dan speaker ponsel Android. Para penyandang tuna netra dapat memanfaatkan alat tersebut untuk menikmati novel audio.

Berikutnya, penelitian (Handayani, Abdullah, \& Hidayanti, 2016) yang meneliti tentang keinginan penyandang disabilitas tunanetra yang beragama menjadi dai atau penyebar agama Islam meskipun dalam keterbatasan. Kendala utama bagi mereka dalam penyebaran Islam adalah komunikasi. Muslim tunanetra sering mengalami kesulitan dalam memperoleh pengetahuan keislaman. Hal ini dikarenakan mereka tidak dapat membaca bukubuku Islam dan terbatasnya buku islam dalam bentuk huruf braille sehingga mereka membutuhkan audiobook yang dapat digunakan saudara muslim tunanetra untuk memperdalam ilmu Islam. Manfaat yang dapat diperoleh dengan adanya audiobook Islami akan memperlancar komunikasi di antara muslim tunanetra dan muslim normal. Sedangkan (Lesmana et al., 2018) memanfaatkan audio yang dikombinasikan dengan visual untuk mengembangkan aplikasi video reality untuk terapi penderita stroke.

Perbedaan penelitian ini dengan penelitian terdahulu yang telah dipaparkan, selain objek penelitian yang berbeda, perbedaan lain yakni dari segi fitur aplikasi dan juga teknologi yang digunakan 
untuk mengembangkan aplikasi audiobook dongeng. WCF mampu memberikan layanan yang dapat diakses oleh aplikasi audiobook dongeng dari berbagai platform, seperti desktop, web, dan mobile.

\section{TINJAUAN PUSTAKA}

\subsection{Audiobook}

Audiobook adalah rekaman isi buku atau tulisan dalam bentuk audio yang dapat didengarkan oleh audien baik berupa teks, gambar, foto, atau ilustrasi lainnya berbentuk suara. Substansi audiobook sama persis seperti yang ada dalam buku teks akan tetapi kata yang diucapakan tidak selalu sama persis dengan versi bukunya (Anwas, 2014).

Menurut Rubery sebagaimana dikutip Anwas, audiobook secara umum digolongkan menjadi dua jenis yaitu unabridge dan abridge. Unabridge adalah jenis audiobook yang buku cetaknya dibacakan secara lengkap, sedangkan abridge adalah jenis audiobook dalam pembacaannya buku cetaknya dibatasi. Pengurangan ini tidak mengurangi tujuan atau makna dari isi audiobook itu sendiri. Akan tetapi pengurangan ini didasarkan pada meringkas isi buku agar lebih mudah dipahami (Anwas, 2014).

\subsection{Dongeng}

Dongeng merupakan alat yang dapat digunakan untuk mendistribusikan ajaran moral dengan cara menyampaikan cerita fiksi sederhana yang menghibur (Triyanto, 2007). Dongeng merupakan bentuk karya sastra yang selain menghibur dapat digunakan sebagai media untuk mengajarkan nilainilai atau sikap luhur yang dipercayai kebenarannya oleh masyarakat. Berdasarkan misi tersebut, dongeng harus memiliki ajaran moral. Penderitaan tokoh, nilai-nilai kejujuran, ketahanan terhadap ujian, imbalan dan hukuman sering dikisahkan di dalam dongeng untuk memberikan pendidikan moral. Sikap dan sifat yang luhur akan menuai benih yang baik, sedangkan sikap yang buruk/tercela akan mendatangkan hukuman.

Manfaat dongeng antara lain sebagai media untuk menanamkan moral dan etika seperti kejujuran, rendah hati, kesopanan, dan lain-lain. Selain itu manfaat dongeng adalah untuk mengenalkan bentuk emosi kepada anak seperti marah, sedih, bahagia, dan lain-lain. Dongeng juga dapat mendekatkan hubungan anak dengan orang tua. Manfaat lainnya adalah untuk memperbanyak kosa kata, melalui dongeng orang tua dapat mengenalkan kosa kata baru pada anak. Dongeng juga dapat digunakan untuk merangsang daya imaginasi anak serta menumbuhkan minat baca sejak dini (Rosada, 2016).

\subsection{Tunanetra}

Tuna netra merupakan orang yang memiliki indera penglihatan yang tidak mampu berfungsi dengan baik sebagai media penangkap informasi dalam aktivitas keseharian. Apabila ketajaman penglihatan kurang dari 6/21 (mampu melihat huruf pada jarak 6 meter yang sebenarnya dapat dilihat oleh orang normal pada jarak 21 meter), maka orang tersebut dikategorikan sebagai penyandang tuna netra. Penyandang tersebut dikategorikan menjadi 2, yakni buta apabila sama sekali tidak mampu memperoleh impuls dari luar visusnya; dan memiliki kemampuan penglihatan rendah apabila ketajaman penglihatannya kurang dari 6/21 (Somantri, 2006).

Dilihat secara makna kata, tuna netra terdiri dari 2 kata, yakni: (1) Tuna yang bermakna rugi yang selanjutnya diasosiasikan dengan rusak, lenyap, terhalang, tidak memiliki; dan (2) Netra yang bermakna mata. Berdasarkan dua makna kata tersebut dapat disimpulkan bahwa tuna netra merupakan kerugian yang bersumber dari kerusakan atau gangguan pada mata. Tuna netra dapat pula bermakna rusak atau terlukanya mata yang merupakan panca indera penglihatan yang menimbulkan kemampuan ketajaman penglihatan berkurang atau sama sekali tidak memiliki kemampuan penglihatan (Rudiyanti, 2002).

\subsection{Windows Communication Foundation}

Windows Communication Foundation (WCF) merupakan teknologi yang dikembangkan oleh Microsoft untuk melakukan komunikasi data berbasis arsitektur yang berorientasi terhadap layanan atau Service Oriented Architecture (SOA). (Tao, dkk., 2014; Purwati dan Utomo, 2014). Serupa dengan definisi sebelumnya, disampaikan oleh (Guo, Liu, \& Yan, 2017; Daadoo, 2017), WCF merupakan model pemrograman yang digunakan untuk membangun aplikasi berorientasi layanan.

Arsitektur WCF terdiri dari 5 bagian, yakni activation dan hosting, messaging, service runtime, contracts, dan application (Barbieru, Postolache, \& Radu, 2011). Gambar 1 menunjukkan arsitektur WCF secara lengkap.

Contracts mendefinisikan seluruh aspek yang berkaitan dengan sistem pesan (message). Lapisan Service Runtime berisi perilaku (behaviors) yang terjadi selama operasi layanan. Selanjutnya, Lapisan messaging terdiri dari banyak kanal. Kanal tersebut adalah komponen yang memproses pesan dengan cara tertentu, misalnya dengan mengautentikasi pesan. Lapisan Hosting dan Activation merupakan operasi aktivasi dan hosting untuk aplikasi WCF. Operasi ini terdiri dari 2 model, yakni self-hosted service jika layanan dieksekusi melalui file executable, dan hosted jika eksekusi aplikasi diatur oleh agen eksternal seperti Internet Information Services (IIS) atau Windows Activation Service (WAS). IIS merupakan web server yang berjalan di lingkungan Microsoft Windows yang digunakan untuk hosting aplikasi berbasis web dan layanan (Defu, Chiam, \& Seng, 2015; Lin, dkk., 2017; Balu dan Saraswathi, 2012; Kaur dan Garg, 2015), 
sedangkan WAS merupakan mekanisme baru untuk mengaktivasi aplikasi atau pesan selain menggunakan protokol Transmission Control Protocol (TCP) (Raju dan Govindarajulu, 2016).
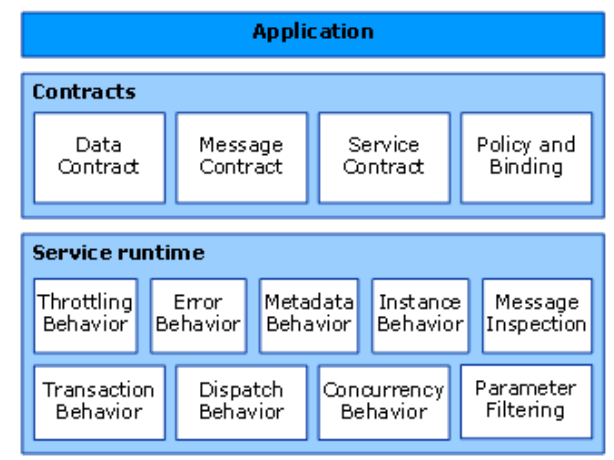

\begin{tabular}{|c|c|c|c|c|}
\hline \multicolumn{5}{|c|}{ Messaging } \\
\hline \multicolumn{2}{|c|}{$\begin{array}{c}\text { WS Security } \\
\text { Channel }\end{array}$} & $\begin{array}{l}\text { WS Reliable } \\
\text { Messaging } \\
\text { Channel }\end{array}$ & \multicolumn{2}{|c|}{$\begin{array}{c}\text { Encoders: } \\
\text { Binary/MTOM/Text/ } \\
\text { XML }\end{array}$} \\
\hline $\begin{array}{c}\text { HTTP } \\
\text { Channel }\end{array}$ & $\begin{array}{c}\text { TCP } \\
\text { CHannel }\end{array}$ & $1 \mid \begin{array}{c}\text { Transaction } \\
\text { Flow } \\
\text { Channel }\end{array}$ & $\begin{array}{c}\text { NamedPipe } \\
\text { Channel }\end{array}$ & $\begin{array}{c}\text { MSMQ } \\
\text { Channe }\end{array}$ \\
\hline
\end{tabular}

\begin{tabular}{l}
\hline Activation and hosting \\
\begin{tabular}{|c|c|c|}
\hline $\begin{array}{c}\text { Windows } \\
\text { Activation } \\
\text { Service }\end{array}$ \\
\hline
\end{tabular}
\end{tabular}

Gambar 1. Arsitektur WCF (Sumber: Barbieru, Postolache, \& Radu, 2011; Microsoft, 2017))

Windows Communication Foundation telah banyak diterapkan di berbagai bidang, seperti perbankan (Medhi, Bora, \& Bezboruah, 2016), kesehatan (Lee, dkk., 2017; Zhang, dkk., 2019), rekam medis elektronik (Wu, dkk., 2017), keamanan data dan informasi (Yeşiltepe, Kaçmaz, \& Kurulay, 2016), dan industri (Guo, Liu, \& Yan, 2017; Park, dkk., 2019). Penggunaan WCF di berbagai bidang telah membuktikan bahwa teknologi layanan tersebut handal dalam komunikasi data antar platform.

\section{METODE PENELITIAN}

Penelitian ini dilakukan dengan 3 tahapan yaitu: (1) analisis sistem yaitu dengan menganalisa kebutuhan fungsional dan non fungsional sistem serta kebutuhan pengguna (user) sistem; (2) desain sistem berisi diagram yang menggambarkan sistem mulai dari use case, sequence, class diagram dan skema layanan $W C F$; dan (3) implementasi dan pengujian. Tahapan dalam riset ini dideskripsikan melalui Gambar 2.

Pada penelitian ini, pengembangan aplikasi WCF menggunakan Microsoft Visual Studio 2012, sedangkan database server menggunakan Microsoft SQL Server. Pengujian aplikasi WCF audiobook dongeng menggunakan tools WCF test client yang telah terintegrasi pada Microsoft Visual Studio.

Data audio yang digunakan dalam penelitian ini berisi dongeng yang berasal dari suara rekaman relawan. Relawan tersebut berasal dari anggota komunitas Ibu Profesional Kelas Bunda Sayang angkatan ke 3, wilayah Jawa Tengah. Terdapat tujuh data audio dengan konten dongeng dan ukuran data yang berbeda. Tabel 1 menjelaskan tentang kelima data tersebut.

ANALISIS SISTEM
Analisa ksbutuhan fungsional
Analisa ksbutuhan non fungsional
Analisa kebutuhan pengguna

\section{HASIL DAN PEMBAHASAN}

\subsection{Analisis Sistem}

Tujuan tahap analisis sistem yakni untuk mengetahui dan menginterpretasikan spesifikasi kebutuhan sistem mutakhir yang digunakan sebagai informasi untuk membangun sistem sesuai dengan spesifikasi tersebut, dilihat dari sisi spesifikasi sistem dan spesifikasi kebutuhan pengguna. Spesifikasi sistem WCF audiobook dongeng antara lain sebagai berikut:

\subsubsection{Analisis Kebutuhan Fungsional}

Kebutuhan fungsional sistem adalah: (1) layanan harus bisa melakukan upload audio dongeng; (2) layanan harus bisa melakukan download audio dongeng; dan (3) layanan harus bisa diimplementasikan pada aplikasi client dengan berbagai device (desktop, web, atau mobile)

\subsubsection{Analisis Kebutuhan Non Fungsional}

Kebutuhan non fungsional sistem meliputi kebutuhan perangkat Keras (Hardware) seperti komputer yang berfungsi untuk mengakses layanan WCF yang akan digunakan pada aplikasi audiobook dongeng dan perangkat lunak (Software) seperti Sistem Operasi Windows 7 dan Browser Chrome/Firefox. 


\subsubsection{Analisis Kebutuhan Pengguna}

Pengguna layanan WCF ini adalah pengembang aplikasi yang akan membangun aplikasi client audiobook dongeng.

\subsection{Desain Sistem}

Perancangan sistem menggunakan Unified Modelling Language (UML) yang terdiri diagram yaitu diagram use case, diagram sequence, dan diagram class. UML merupakan notasi grafis yang mendeskripsikan desain pengembangan sistem menggunakan pemrograman berorientasi objek (Pradana, Priyambadha, \& Rusdianto, 2016).

\subsubsection{Use Case Model}

Layanan $W C F$ yang bisa dimanfaatkan oleh pengguna antara lain menambah audio dongeng, mendengar audio dongeng dan melihat daftar audio dongeng. Gambar 3 menunjukkan diagram use case layanan audiobook dongeng. Diagram ini menjelaskan bagaimana pengguna dapat berinteraksi dengan sistem (Antono, Wicaksono, \& Pinandito, 2018) dan mendeskripsikan fitur yang terdapat di dalam suatu sistem.

\subsubsection{Sequence Diagram}

Gambar 4 menunjukkan pengguna dapat menambahkan audio dongeng dengan melakukan invokasi terhadap layanan WCF setAudio pada Servicel.SVC, selanjutnya layanan akan memberikan nilai kembalian berupa data audio yang tersimpan di dalam basis data.

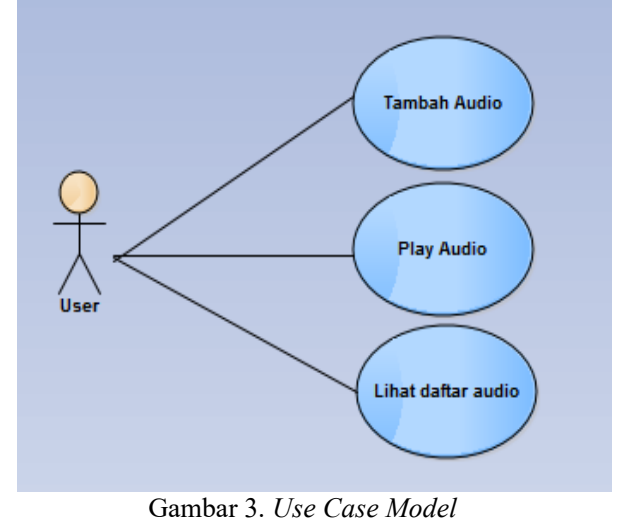

Gambar 5 menunjukkan pengguna dapat memilih dan mendengarkan audio dongeng dengan melakukan invokasi terhadap layanan WCF getAudio pada Service1.SVC, selanjutnya layanan akan memberikan nilai kembalian berupa data audio dongeng yang terpilih untuk didengarkan.

Gambar 6 menunjukkan pengguna dapat melihat daftar audio dongeng dengan melakukan invokasi terhadap layanan WCF getAudioList pada Service1.SVC, selanjutnya layanan akan memberikan nilai kembalian berupa daftar audio dongeng yang tersimpan di dalam basis data.

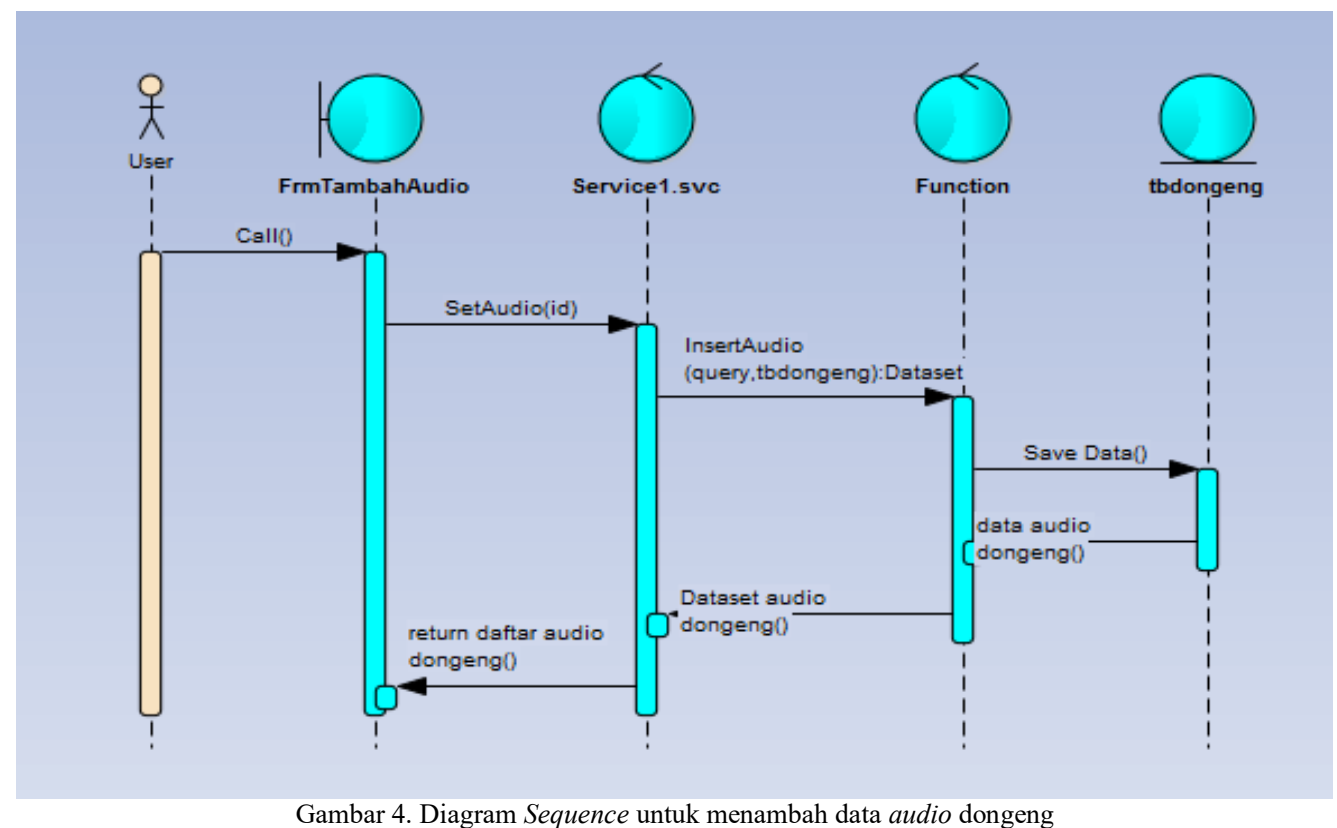

Gambar 4. Diagram Sequence untuk menambah data audio dongeng 


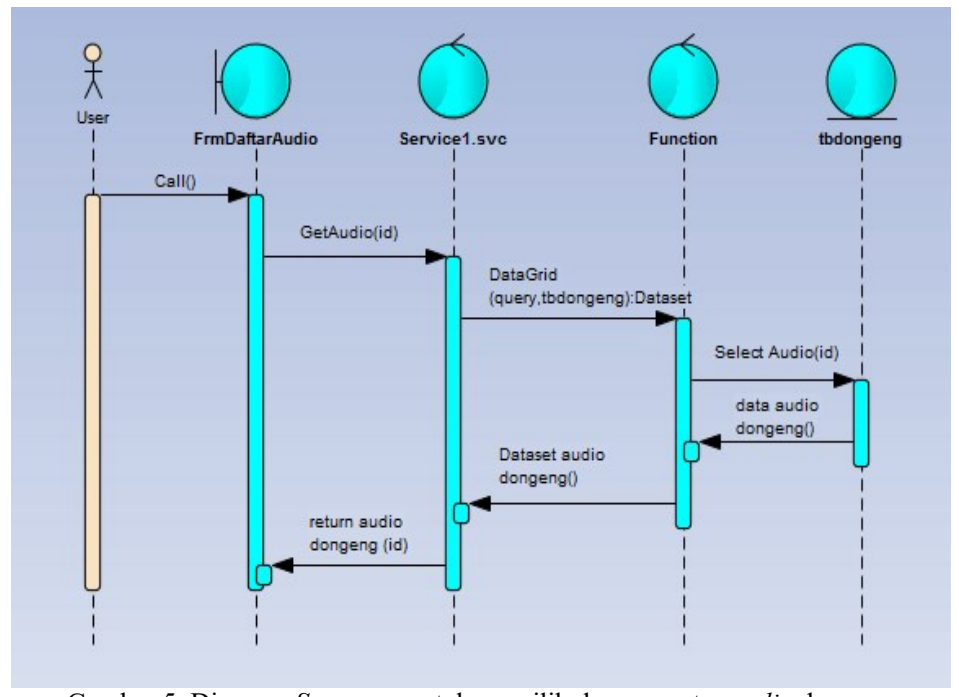

Gambar 5. Diagram Sequence untuk memilih dan memutar audio dongeng

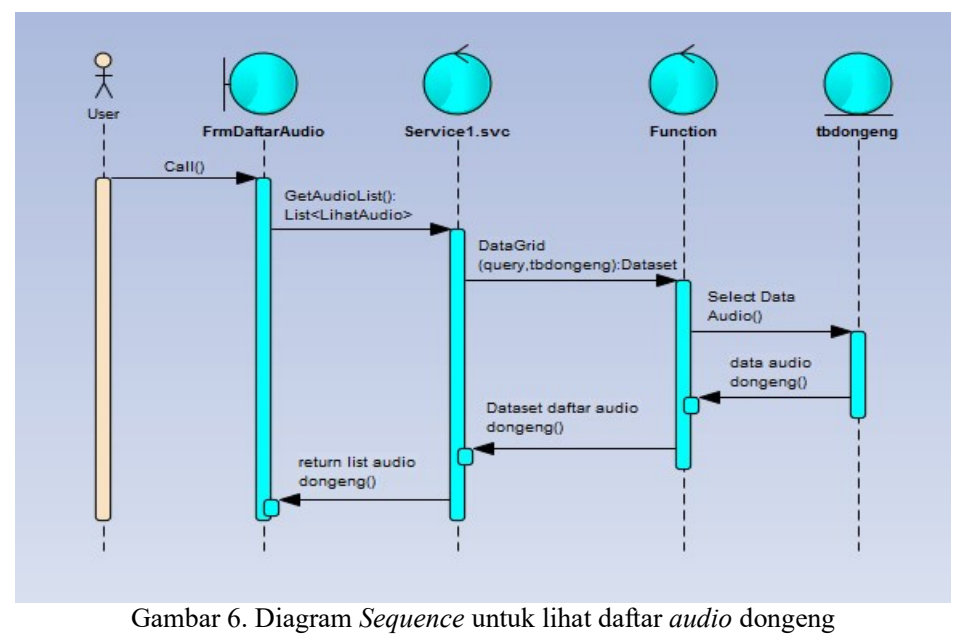

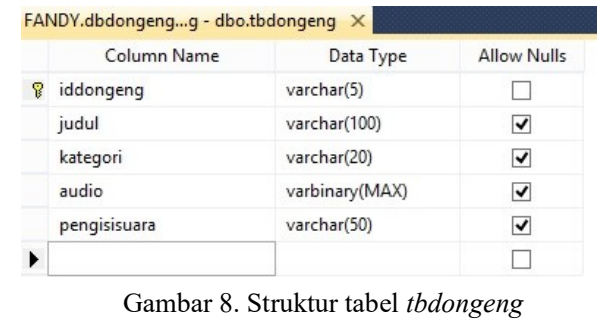

Selanjutnya, Gambar 9 menjelaskan contoh kode program untuk method getAudioList() pada class Service1.svc.

Pada Gambar 9 tampak method tersebut memberikan tipe data kembalian berupa List yang berisi daftar profil audio dongeng.

\subsubsection{Skema layanan WCF service audiobook dongeng}

Gambar 10 merupakan skema WCF Sevice untuk audiobook dongeng. Berdasarkan analisis kebutuhan pengguna maka service yang dikembangkan adalah setAudio untuk menambahkan data dongeng, getAudio untuk memutar audio dongeng, getAudioList untuk menampilkan daftar audio dongeng yang dapat diakses melalui platform mobile, web, dan desktop.

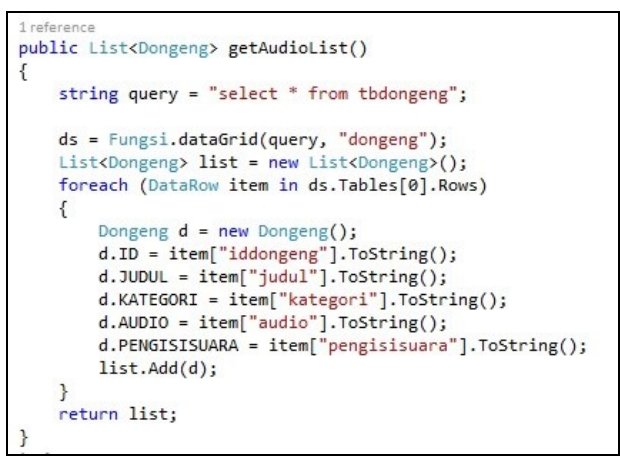

Gambar 9. Kode program getAudioList()

\subsection{Implementasi dan Pengujian}

Berdasarkan analisis kebutuhan pengguna melalui diagram use case pada Gambar 3 dan daftar layanan pada Gambar 7, kami mengembangkan tiga layanan pada WCF yang dapat dikonsumsi oleh aplikasi client, baik pada platform mobile, web, maupun desktop. Pengembangan WCF untuk audiobook dongeng menggunakan pemrograman 
C\#.NET pada lingkungan framework .NET. Protokol, format pesan, nama layanan, dan deskripsi masing-masing layanan dijelaskan pada Tabel 2.

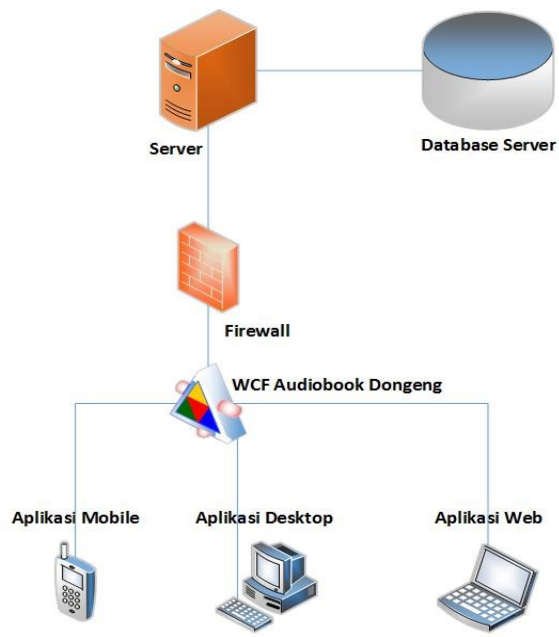

Gambar 10. Skema WCF Sevice untuk audiobook dongeng.

\begin{tabular}{lccl} 
Protokol & \multicolumn{3}{c}{ Tabel 2. Daftar Layanan } \\
\hline SOAP & XML & $\begin{array}{c}\text { Nama } \\
\text { Layanan }\end{array}$ & \multicolumn{1}{c}{ Deskripsi } \\
\hline SOAP & XML & getAudio() & $\begin{array}{l}\text { Layanan menambah } \\
\text { data audio dongeng } \\
\text { Layanan memutar } \\
\text { data audio dongeng } \\
\text { Layanan melihat } \\
\text { daftar audio } \\
\text { dongeng }\end{array}$ \\
\hline
\end{tabular}

Terdapat 2 jenis protokol pertukaran pesan di dalam layanan WCF, yaitu Simple Object Access Protocol (SOAP) dan REpresentational State Transfer (REST). Di dalam penelitian ini protokol SOAP digunakan pada proses pertukaran pesan. SOAP adalah protokol yang digunakan untuk pertukaran pesan atau data dalam format Extensible Markup Language (XML) di dalam jaringan dan menyediakan skema pengkodean yang memungkinkan tervalidasi secara selektif oleh firewall (Barbaglia, Murzilli, \& Cudini, 2017; Fahad, Moalla, \& Ourzout, 2015). Lebih spesifik disampaikan oleh (Nabi, dkk., 2010; Pal dan Karakostas, 2014), bahwa SOAP merupakan protokol komunikasi dengan format pengkodean XML untuk interaksi antara 2 atau lebih entitas perangkat lunak/aplikasi jaringan. Komunikasi antar entitas perangkat lunak yang dimaksud menurut (Khan dan Abbasi, 2015; Shahid et al., 2018), yakni komunikasi antara aplikasi client dengan layanan web. Protokol SOAP merupakan cara berkomunikasi antar perangkat lunak di dalam jaringan menggunakan Hypertext Transfer Protocol (HTTP) tanpa kendala perbedaan sistem operasi (Khan dan Abbasi, 2015; Thomas dan Immanuel, 2017).

Pengujian dilakukan dengan memanggil layanan setAudio untuk menambahkan data dongeng, getAudio untuk memutar dongeng, dan getAudioList untuk menampilkan data dongeng. Gambar 11 menunjukkan contoh pengujian layanan
WCF getAudioList untuk menampilkan daftar audio dongeng menggunakan aplikasi WCF Test Client.

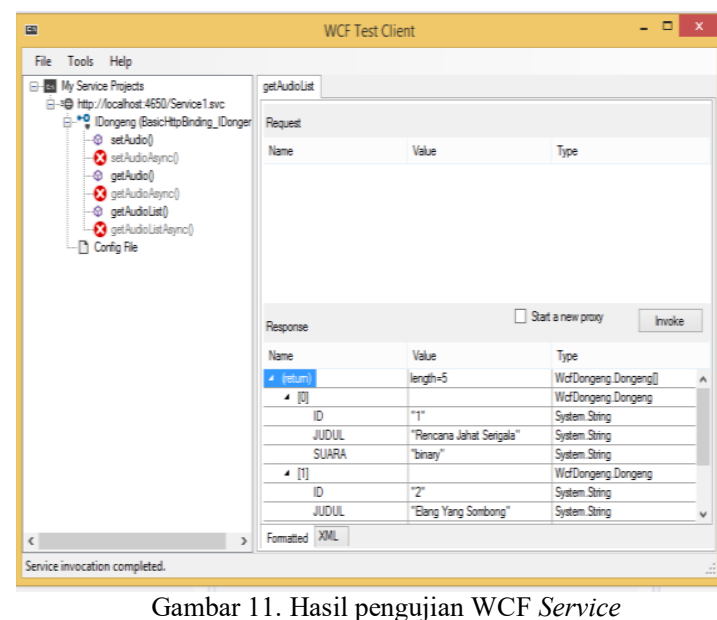

Gambar 11 menunjukkan hasil pengujian untuk mengakses layanan getAudioList. Pemanggilan layanan tersebut dilakukan tanpa menggunakan parameter tertentu. Terdapat 2 jendela di sisi panel sebelah kanan, yakni jendela "Request" dan jendela "Response." Jendela "Request" berfungsi untuk menampilkan daftar parameter, tipe data parameter, dan nilai parameter yang digunakan untuk memanggil layanan, sedangkan jendela "Response" berfungsi untuk menampilkan data keluaran dari hasil pemanggilan layanan. Pada Gambar 11, struktur data dan data mengenai daftar audio dongeng ditampilkan secara terstruktur. Berdasarkan hasil pengujian terhadap layanan tersebut, dapat disimpulkan bahwa layanan getAudioList dapat berfungsi dan mampu memberikan informasi pengguna.

Selain WCF Test Client mampu menampilkan hasil pengujian layanan dalam format data terstruktur, aplikasi tersebut juga mampu menampilkan hasil pengujian dengan format XML. Gambar 12 menunjukkan hasil pengujian layanan WCF getAudioList dalam format XML.

Berdasarkan Gambar 12 dapat dijelaskan bahwa jendela "Request" dan "Response" berisi pesan dalam format XML. Pada jendela "Request" ditampilkan daftar parameter, tipe data parameter, dan nilai parameter yang digunakan untuk memanggil layanan dalam format XML, sedangkan jendela "Response" menampilkan data keluaran dari hasil pemanggilan layanan dalam format XML. Berikut merupakan kode XML pada bagian SOAP Request yang digunakan untuk memanggil layanan.

$<\mathrm{s}:$ Envelope

xmlns:s="http://schemas.xmlsoap.org/soap/envelope/">

$<$ s:Header $>$

$<$ Actions:mustUnderstand="1"

$\mathrm{xmlns}=$ "http://schemas.microsoft.com/ws/2005/05/addressing/non

$\mathrm{e}$ ">http://tempuri.org/IDongeng/getAudioList $</$ Action $>$

$</$ s:Header $>$

$<$ s:Body $>$

$<$ getAudioList xmlns="http://tempuri.org/" />

$</$ s:Body $>$

$</$ s:Envelope $>$ 


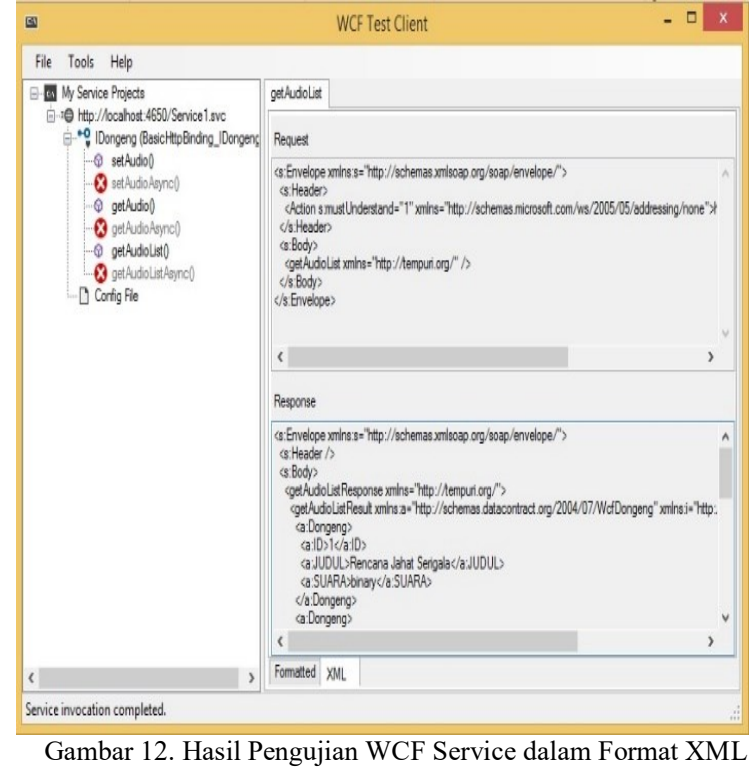

Dokumen SOAP Response sebagai hasil keluaran pemanggilan layanan dalam format XML disajikan sebagai berikut.

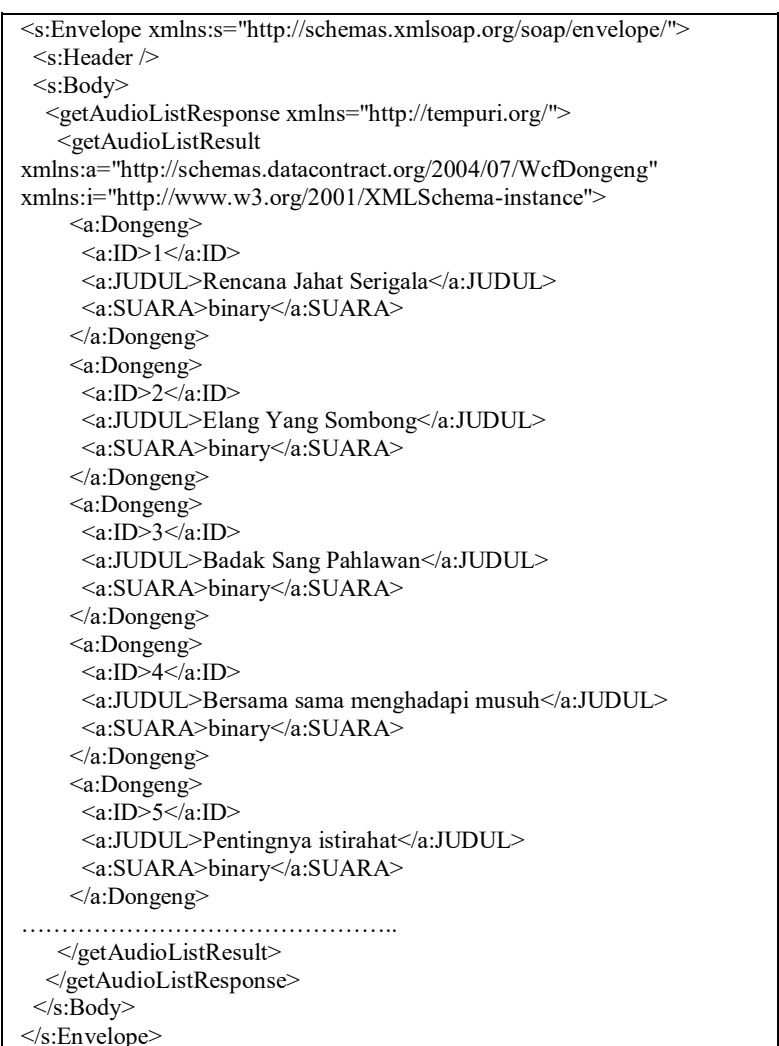

Berdasarkan keluaran hasil eksekusi layanan getAudioList dalam format XML, tampak struktur data seperti ID, judul, dan suara. Selain menampilkan struktur data, kode XML juga menampilkan data daftar audio dongeng.

\section{KESIMPULAN}

Berdasarkan pembahasan pada bagian implementasi dan pengujian, maka dapat ditarik kesimpulan penelitian ini menghasilkan 3 layanan yaitu setAudio untuk menyimpan data dongeng, getAudio untuk memutar audio dongeng dan getAudioList untuk melihat daftar audio dongeng yang seluruh layanannya dapat berfungsi dengan baik dan mampu memberikan informasi kepada pengguna. Layanan yang dibuat sesuai kebutuhan aplikasi audiobook dongeng. Saran yang perlu diberikan demi keberlanjutan penelitian berikutnya adalah untuk mengembangkan aplikasi client pada platform mobile, web, dan desktop yang mengakses layanan WCF agar dapat digunakan oleh pengguna akhir untuk mengakses informasi audiobook dongeng.

\section{UCAPAN TERIMAKASIH}

Kami berterimakasih kepada LPPM STMIK AMIKOM Purwokerto yang telah memberikan dana untuk penelitian ini melalui program Hibah Penelitian Dosen STMIK AMIKOM Purwokerto dengan Surat Keputusan nomor 055/AMIKOMPWT/LPPM/15/IV/2018.

\section{DAFTAR PUSTAKA}

ANTONO, F. I. D., WICAKSONO, S. A., \& PINANDITO, A. (2018). Development of Academic Assessment Management Information System (Case Study: KB \& TK Permata Iman). Journal of Information Technology and Computer Science, 3(1), pp. 94-103.

ANWAS, OOS. M. (2014). "Audiobook: Media Pembelajaran Masyarakat Modern”. Jurnal Teknodik, 18(1)

AZKIYA, N. R. dan ISWINARTI. (2016). "Pengaruh Mendengarkan Dongeng Terhadap Kemampuan Bahasa Pada Anak Prasekolah". Jurnal Ilmiah Psikologi Terapan, 4(2), ISSN: 2301-8267, pp. 123139.

BALU, V., dan SARASWATHI, M. (2014). Implementation of SAAS Compiler in Intranet. International Journal of Computer Applications, 107(8), pp. 17-19.

BARBAGLIA, G., MURZILLI, S., \& CUDINI, S. (2017). Definition of REST web services with JSON schema. Software: Practice and Experience, 47(6), pp. 907-920.

BARBIERU, D., POSTOLACHE, M., \& RADU, C. (2011, April). New Features of Windows Mobile Platform. In The 7th International Scientific Conference eLearning and Software for Education, pp. 28-29.

CAMALIA, F., SUSANTO, H., \& SUSILO, S. (2016). "Pengembangan Audiobook Dilengkapi Alat Peraga Materi Getaran Dan Gelombang Untuk Tunanetra Kelas VIII 
SMP”. UPEJ Unnes Physics Education Journal, 5(2), pp. 66-75.

DAADOO, M. (2017). Developing and Implementation of Distributed Chat Applications using WPF and WCF. European Journal of Scientific Research, 143(4), pp. 424-440.

DEFU, W., CHIAM, K., \& SENG, Y. K. (2015). Building an Interactive Web-Based GIS System for Planning of Geological Survey Works. World Academy of Science, Engineering and Technology-International Journal of Civil and Architectural Engineering, 9(3), pp. 712-715.

FAHAD, M., MOALLA, N., \& OURZOUT, Y. (2015). Dynamic Execution of a Business Process via Web Service Selection and Orchestration. Procedia Computer Science, 51, pp. 1655-1664.

GUO, N., LIU, Y. H., \& YAN, M. H. (2017). Chip Manufacturing, Data Integration and Transmission. In Current Trends in Computer Science and Mechanical Automation, 2, pp. 41-51.

FITROH, S. F. dan SARI, E. D. N. (2015). "Dongeng Sebagai Media Penanaman Karakter Pada Anak Usia Dini”. Jurnal PGPAUD Trunojoyo, 2(2), pp. 76-149.

HANDAYANI, M. R., ABDULLAH, A. D., \& HIDAYANTI, E. (2016). "Implementasi Audiobook Islami Sebagai Media Pelatihan Berdakwah Muslim Tunanetra". Dimas: Jurnal Pemikiran Agama untuk Pemberdayaan, 16(1), pp. 1-26

INDRIASTUTI, F. (2015). "Cerita Rakyat Dalam Format Buku Audio Digital Untuk Belajar Bahasa Inggris". Jurnal Teknodik, 19(2), pp. 183-194

KAUR, J., dan GARG, K. (2015). Analyzing the Different Attributes of Web Log Files to Have an Effective Web Mining. International Journal of Advanced Scientific and Technical Research, 3(5), pp. 127-134.

KHAN, M. W., dan ABBASI, E. (2015). Differentiating Parameters for Selecting Simple Object Access Protocol (SOAP) vs. Representational State Transfer (REST) Based Architecture. Journal of Advances in Computer Networks, 3(1), pp. 63-66.

LEE, K., JUNG, S. Y., HWANG, H., YOO, S., BAEK, H. Y., BAEK, R., \& KIM, S. (2017). A novel concept for integrating and delivering health information using a comprehensive digital dashboard: An analysis of healthcare professionals' intention to adopt a new system and the trend of its real usage. International
Journal of Medical Informatics, 97, pp. 98108.

LESMANA, I.P.D., WIDIAWAN, B., HARTADI, D.R. dan HARIS, M.F. AL, (2018). Pengembangan Terapi Cermin Pada Latihan Bersepeda Berbasis Virtual Reality Untuk Meningkatkan Gerak Motorik Ekstremitas Atas Pasca Stroke. Jurnal Teknologi Informasi dan Ilmu Komputer, 5(4), pp.503-509.

LIN, S. S., LAN, C. W., CHEN, P. N., HUNG, M. H., TAN, K. H., WU, Y. H., \& NIEH, J. Y. (2017). Development of a Novel Power-Monitoring System Using Internet and Wireless Sensor Network Technologies. Sensors and Materials, 29(7), pp. 1005-1015.

MEDHI, S., BORA, A., \& BEZBORUAH, T. (2016). Security Impact on e-ATM Windows Communication Foundation Services using Certificate based Authentication and Protection: An implementation of Message Level Security based on. NET Technique. International Journal of Information Retrieval Research (IJIRR), 6(3), pp. 37-51.

MICROSOFT. Windows Communication Foundation Architecture. Internet: https://docs.microsoft.com/enus/dotnet/framework/wcf/architecture, Mar. 3, 2017 [Oct. 31, 2018].

NABI, M. S. A., KIAH, M. M., ZAIDAN, B. B., ZAIDAN, A. A., \& ALAM, G. M. (2010). Suitability of using SOAP protocol to secure electronic medical record databases transmission. Int. J. Pharmacol, 6(6), pp. 959-964.

PAL, K., dan KARAKOSTAS, B. (2014). A multi agent-based service framework for supply chain management. Procedia computer science, 32, pp. 53-60.

PARAMITHA, A.A.I.I., KESIMAN, M.W.A. dan ARTHANA, I.K.R., (2014). Pengembangan "Digital Interactive Storyteller" Berbasis Android Untuk. Jurnal Nasional Pendidikan Teknik Informatika (JANAPATI), [online] 3(3), pp.142-149. Available $<$ https://ejournal.undiksha.ac.id/index.php/j anapati/article/view/9824/6247>.

PARK, K. T., IM, S. J., KANG, Y., NOH, S. D., KANG, Y. T., \& YANG, S. G. (2019). Service-oriented platform for smart operation of dyeing and finishing industry. International Journal of Computer Integrated Manufacturing, 32(3), pp. 307-326.

PRADANA, F., PRIYAMBADHA, B., \& RUSDIANTO, D. S. (2016). Identifying Thresholds for Similarity-Based Class Cohesion (SCC) Metrics. Journal of 
Information Technology and Computer Science, 1(2), pp. 72-81.

PRATAMA, D., HAKIM, D. A., PRASETYA, Y., FEBRIANDIKA, N. R., TRIJATI, M., \& FADLILAH, U. (2016). "Rancang Bangun Alat dan Aplikasi untuk Para Penyandang Tunanetra Berbasis Smartphone Android". Khazanah Informatika: Jurnal Ilmu Komputer dan Informatika, 2(1), pp. 14-19.

PURWATI, Y., dan UTOMO, F.S. (2014). Windows Communication Foundation for Banyumas Tourism and Culinary Information System. TELKOMNIKA, 12(4), pp. 1031-1038.

RAJU, P. B. S., \& GOVINDARAJULU, P. (2016). Performance Evaluation of Web Services In Linux On Multicore. International Journal of Computer Science \& Security, 10(4), pp. 161-169.

ROSADA, U. D. (2016). "Memperkuat Karakter Anak Melalui Dongeng Berbasis Media Visual". Jurnal CARE (Children Advisory Research and Education), 4(1), pp. 42-49.

RUDIYANTI, S. (2002). Pendidikan Anak Tunanetra. Yogyakarta: Fakultas Ilmu Pendidikan Universitas Negeri Yogyakarta.

SHAHID, K., OLSEN, R. L., PETERSEN, L., \& IOV, F. (2018). ICT Requirements and Challenges for Provision of Grid Services from Renewable Generation Plants. In 2018 International Conference on Smart Grid and Clean Energy Technologies (ICSGCE), pp. 23-31. IEEE Computer Society.

SOMANTRI, S. (2006). Psikologi Anak Luar Biasa. Bandung: PT Refika Aditama.

TAO, X., XIN, H., JIWEN, X., \& SHUJUAN S. (2014). Security Interaction of Web Services in Heterogeneous Platforms. TELKOMNIKA, 12(4), pp. 2868-2874.

THOMAS, L., \& IMMANUEL, A. (2017). Web Service Composition: A Survey on the Various Methods used for Web Service Composition. International Journal of Advanced Research in Computer Science, 8(3), pp. 665-670.

TRIYANTO, A. (2007). Bahasa Indonesia Tingkat SMP. Jakarta: PT. Gramedia.

WU, C. H., CHIU, R. K., YEH, H. M., \& WANG, D. W. (2017). Implementation of a cloudbased electronic medical record exchange system in compliance with the integrating healthcare enterprise's cross-enterprise document sharing integration profile. International journal of medical informatics, 107, pp. 30-39.

YEŞILTEPE, M., KAÇMAZ, E., dan KURULAY, M. (2016). Study triple data encryption standart encryption algorithm in windows communication foundation environment. In 2016 Electric Electronics, Computer Science, Biomedical Engineering' Meeting (EBBT), pp. 1-4. IEEE Computer Society.

ZHANG, P., ZHANG, Y., LIAO, L. M., SHEN, J., YANG, Y., ZHANG, J., WU, L., \& ZHANG, X. (2019). Application of Internet+-based Tsinghua PINS Remote Tech to improve sacral neuromodulation programming procedure. International urology and nephrology, 51(4), pp. 627632. 